\title{
In-situ nanocomposite in friction stir welding of 6061-T6 Aluminum alloy to AZ31 magnesium alloy
}

\author{
A. Abdollahzadeh ${ }^{1,2}$, A. Shokuhfar ${ }^{1}$, J.M. Cabrera ${ }^{2}$, A.P. Zhilyaevv ${ }^{2,3}$, H. Omidvar ${ }^{4}$ \\ ${ }^{1}$ Faculty of Materials Science and Engineering, K. N. Toosi University of Technology, Tehran, Iran. \\ ${ }^{2}$ Department of Materials Science and Metallurgical Engineering, Polytechnic University of Catalonia, Barcelona, \\ Spain. \\ ${ }^{3}$ Institute for Problems of Metals Superplasticity, Russian Academy of Sciences, Ufa, Russia. \\ ${ }^{4}$ Faculty of Mining and Metallurgical Engineering, Amirkabir University of Technology, Tehran, Iran.
}

Corresponding authors*: aabdollahzadeh@mail.kntu.ac.ir, shokuhfar@kntu.ac.ir, Tel: + 982184063224.

\begin{abstract}
Prior to friction stir welding (FSW), silicon carbide ( $\mathrm{SiC}$ ) nanopowders were placed inside the groove on the adjacent side of magnesium sheet. In order to make a good distribution of these nanoparticles, first, friction stir processing (FSP) with a pinless tool was conducted on this side. Second, using a frustum pin tool, a combination of two travel speeds (25 and $35 \mathrm{~mm} / \mathrm{min})$ and three rotation speeds (550, 600 and $650 \mathrm{rpm})$ were employed to obtain the optimal conditions for FSW of AZ31 magnesium alloy to 6061 aluminum alloy. The joint fabricated at $35 \mathrm{~mm} / \mathrm{min}$ and 650 rpm, exhibited improvement of $28 \%$ in tensile strength and enhancement about three times in elongation, compared with the joint without nanoparticles. SiC nanoparticles had an effective role on the grain refining of the stirred zone and improving the microstructural characteristics of the banded structure zone. Due to the decreased grain size and the presence of ceramic nanoparticles $(\mathrm{SiC})$ with high value of hardness, the hardness level of the reinforced samples was greater than that of the non-reinforced samples. Fracture of the non-reinforced sample was completely brittle, while in the reinforced samples, fracture features changed to the ductile mode.
\end{abstract}

Keywords: FSW, FSP, Dissimilar A1/Mg joint, SiC nanocomposite, Microstructural characteristics, Mechanical properties.

\section{Introduction}


Dissimilar FSW joints of magnesium and aluminum alloys have been investigated by Chowdhury et al. (2013), Fu et al. (2015), Rao et al. (2015) and Zhao et al. (2015). $\mathrm{Al}_{12} \mathrm{Mg}_{17}$ and $\mathrm{Al}_{3} \mathrm{Mg}_{2}$ intermetallic phases have been reportedly formed (Buffa et al., 2015; Dorbane et al., 2016; Firouzdor and Kou, 2010a; Liang et al., 2013; Mofid et al., 2012) during FSW operations. These intermetallic compounds (IMC) can be limited by the heat input controlling process parameters, such as pass number of FSW. Reducing the pass number of FSW causes the limited formation of IMCs because of lower heat risings and less interaction between materials. Two other important factors are the traveling and rotational speeds of the tool. For instance, the effects of tool rotational speed and offset on improving mechanical properties of Mg-Al FSW joints have been investigated by Liang et al. (2013). They identified three weak/critical zones inside the joints: (1) the bottom interface (BI) zone due to poor $\mathrm{Mg} / \mathrm{Al}$ interdiffusion and intermixing, (2) the banded structure (BS) zone containing a lot of IMC compounds potentially shaped by constitutional liquation (liquid film formation at the interface of magnesium and aluminum far from the melting points), and (3) the softened $\mathrm{Al}$ alloy (SAA) zone resulting from the coarsening and dissolution of the reinforcing precipitates. The majority of the samples experienced a brittle fracture in the BS zone. Thus, it was suggested that an effective route for improving the mechanical properties of $\mathrm{Mg} / \mathrm{Al}$ friction stir welded joints was to improve the mechanical strength of each zone; especially the BS.

Fracture, mechanical and microstructural properties of dissimilar joints processed by FSW of magnesium AZ31 and aluminum 6061 have been evaluated by Dorbane et al. (2016). Different parameters and material configurations resulted in successful welding. Brittle fracture was shown to occur in the samples examined under tensile loading where samples fractured along the welded joint and the cracks were observed to start in the IMCs.

FSW of AZ31 to A16061, considering the effects of welding condition, was also investigated by Firouzdor and Kou (2010), who reported the presence of a eutectic structure and the formation of IMC composed by $\mathrm{Al}_{12} \mathrm{Mg}_{17}$ and $\mathrm{Al}_{3} \mathrm{Mg}_{2}$ inside the nugget zone. The significant effect of welding conditions, i.e. material position, rotational and traveling speeds, on heat input was also observed. They concluded that the heat input is the key parameter representing the relation between the joint strength and the welding conditions.

A new techniqe first reported by Sun and Fujii (2011) improve the joint properties by introducing ceramic particles as reinforcement inside the weld during FSW to make metal matrix composite inside the stirring zone (SZ). Bahrami et al. (2014b) recently showed that 7075 aluminum alloy plates were effectively welded by the addition of $\mathrm{SiC}$ nanoparticles into the joint. They observed crucial improvement in the mechanical properties of the joints. They 
reported an increment of both $31 \%$ in tensile strength (UTS) and $76.1 \%$ in elongation when FSW was accomplished at travel and rotation speeds of $40 \mathrm{~mm} / \mathrm{min}$ and $1250 \mathrm{rpm}$, respectively. They also evaluated the positive effect of pin geometry by using threaded taper pin tool (Bahrami et al., 2014a).

The effect of travel and rotation speeds on microstructure and mechanical features of AZ31 reinforced with SiC and welded by FSW was investigated by Abbasi et al. (2016, 2015). They pointed out the very small grain sizes obtained further to the uniform dispersion of the reinforcements inside the stirring zone by using travel and rotation speeds of $75 \mathrm{~mm} / \mathrm{min}$ and $800 \mathrm{rpm}$, respectively.

Moradi et al. (2017) investigated the effect of nano and micro scale SiC particles on the mechanical and microstructural issues of dissimilar FSW of 2024 to 6061 aluminum alloys and observed a significant diminution of the grain size inside the stirring zone in both AA6061 and AA2024 sides. Meanwhile, the grain size in this zone decreased by 25 and $16 \%$, respectively, with addition of nano and micro scale $\mathrm{SiC}$ while the joints containing $\mathrm{SiC}$ showed higher tensile strength and toughness compared with $\mathrm{SiC}$ free joints.

The effect of SiC nano powder on FSW of dissimilar A316L stainless steel to Al alloy was studied by Fallahi et al. (2017). They found out that the welding travel speed played a key role in the distribution of the reinforcement particles and mechanical strength of dissimilar joints. They concluded that one effective route to enhance the mechanical properties of dissimilar bimetallic AA5083-A316L joint is the introduction of a composite stirred zone by applying $\mathrm{SiC}$ reinforcement.

Although a number of researchers have sought to investigate similar FSW of aluminum alloys with reinforcement particles in the stirring zone, few works have been conducted on the incorporation of nanoparticles into a dissimilar FSW process. To the best of the authors' knowledge, nanoparticles have not been previously used as reinforcement in dissimilar FSW of AZ31 magnesium alloy to 6061 aluminum alloy. The purpose of this research is to study the potential of fabricating in situ nanocomposites inside a dissimilar FSW joint of AZ31 magnesium alloy to 6061 aluminum alloy. To make a better dispersion of the reinforcement particles inside the stirring zone, a novel method involving both Friction Stir Processing (FSP) and FSW processes was applied. At first, an appropriate distribution of particles was created on the faying surface of the Mg alloy strip using several passes of the FSP process, followed by performing FSW process on the dissimilar strips put together. Meanwhile, to gain a perfect joint with a uniform stirring zone, the effect of travel and rotation speeds on macrostructure, microstructure and mechanical behavior (tensile tests 
and hardness) of the nano reinforced welds were examined. For comparison purposes, an optimized joint free of $\mathrm{SiC}$ nanoparticles was also prepared and tested.

\section{Experimental Procedure}

$5 \mathrm{~mm}$ thick sheets of AZ31 Mg alloy and 6061-T6 Al alloy were cut into samples with a width of $60 \mathrm{~mm}$ and a length of $100 \mathrm{~mm}$. Table 1 represents nominal chemical contents and mechanical characteristics of both alloys.

\section{Table 1}

Chemical contents and mechanical characteristics of alloys.

\begin{tabular}{|c|c|c|c|c|c|c|c|c|c|c|c|c|}
\hline \multirow{2}{*}{ alloys } & \multicolumn{9}{|c|}{ Chemical contents (weight percent) } & \multicolumn{3}{|c|}{ Mechanical characteristics } \\
\hline & $\mathrm{Al}$ & $\mathrm{Mg}$ & $\mathrm{Si}$ & $\mathrm{Zn}$ & $\mathrm{Fe}$ & $\mathrm{Cu}$ & $\mathrm{Mn}$ & $\mathrm{Cr}$ & $\mathrm{Ti}$ & $\begin{array}{c}\text { Tensile Strength } \\
\text { (MPa) }\end{array}$ & $\begin{array}{c}\text { Elongation } \\
(\%)\end{array}$ & $\begin{array}{c}\text { Hardness } \\
(\mathrm{HV})\end{array}$ \\
\hline $\mathrm{Al} 6061$ & Bal. & 0.9 & 0.64 & 0.003 & 0.3 & 0.25 & 0.01 & 0.1 & 0.02 & 320 & 14 & 105 \\
\hline Mg AZ31 & 2.84 & Bal. & - & 1.17 & 0.004 & - & 0.15 & - & - & 255 & 12 & 55 \\
\hline
\end{tabular}

A welding procedure including both FSP and FSW was used. In most FSP studies which are used for producing a surface nanocomposite and reviewed by Sharma et al., 2015, the groove configuration is utilized as a container for placement of the nanoparticles. The designed geometry of pin and $5 \mathrm{~mm}$ thickness of sheets were considered for selecting the dimensions of groove. Hence, on the faying surface of the magnesium alloy, a profile with $2 \mathrm{~mm}$ width, $2 \mathrm{~mm}$ depth and $90 \mathrm{~mm}$ length was selected to reach the equal volume fraction of $\mathrm{SiC}$ particles with the related research conducted by Pantelis et al., 2016. $\beta$-SiC nanoparticles were then placed in the groove and pressed tightly

The average diameter of the $\mathrm{SiC}$ particles was below $60 \mathrm{~nm}$. SiC bears lower mismatch (i.e., higher thermal temperature gradients) given the lower thermal expansion in comparison with other ceramics. This shows higher coherency with the matrix, which reduces the possibility of cracking/braking (Tebyani and Dehghani, 2016, 2015). Three passes of FSP process (using a pinless tool) were carried out to close the filled groove, prevent the powder from spattering during FSW and provide a good distribution of nanoparticles on the adjoining side of the magnesium plate.

The applied FSP procedure is presented in Fig. S1.

After grinding and using a purpose built fixture, aluminum and magnesium strips were fixed and the plates were butt welded. A wide range of rotational speeds $(450,550,650,750$ and $850 \mathrm{rpm})$ and traverse speeds $(15,25,35,45$ and 
$55 \mathrm{~mm} / \mathrm{min}$ ) were used in the first step. The dissimilar welding of Al to Mg alloy upon the addition of SiC nanoparticles was observed to be very sensitive to the welding parameter. The samples with rotational speeds of 550 and $650 \mathrm{rpm}$ and the traverse speed of 25 and $35 \mathrm{~mm} / \mathrm{min}$ had appropriate weld appearance, as found by the visual inspection of the welded samples. Therefore, these ranges were then investigated using a combination of two travel speeds ( 25 and $35 \mathrm{~mm} / \mathrm{min}$ ) and three rotation speeds (namely 550, 600 and $650 \mathrm{rpm}$ ), three samples being subjected to each condition. A 3 axis FSW machine (FP4ME-CNC) with spindle power and speed of $4 \mathrm{KW}$ and 5-2800 rpm, respectively, was used for this purpose. To comprehend the influences of $\mathrm{SiC}$ nanoparticles on the microstructural and mechanical characteristics of the welds, friction stir welding was also performed on a sample without applying SiC nanoparticles. A simple schematic representation of the applied FSW/FSP processes is illustrated in Fig. 1. The employed process parameters are listed in Table 2. The FSP parameters have been selected considering study by Azizieh et al., 2011, and FSW parameters have been chosen according to studies of Firouzdor and Kou, 2010a; and Fu et al., 2015. Furthermore, Table 3 summarizes the data related to the samples and processing conditions. Friction stir welding tool was fabricated using H13 steel with a hardness of 50 HRc. Tool details are shown in Table 4. A pinless tool was used in FSP process to close the groove. The frustum pin geometry for FSW was chosen based on research by Bahrami et al., 2014a, also the pin and shoulder dimensions were selected considering design and descriptions presented by Arora et al., 2011; Bahrami et al., 2014a; Elangovan and Balasubramanian, 2008; and Padmanaban and Balasubramanian, 2009. In each experiment, the nanoparticle theoretical volume fraction $\left(\mathrm{V}_{\mathrm{f}}\right)$ in the stir zone, calculated using the ratio of groove area to tool pin projected area, was about $16 \%$, according to Dragatogiannis et al. (2016). This parameter was kept steady under all conditions. 


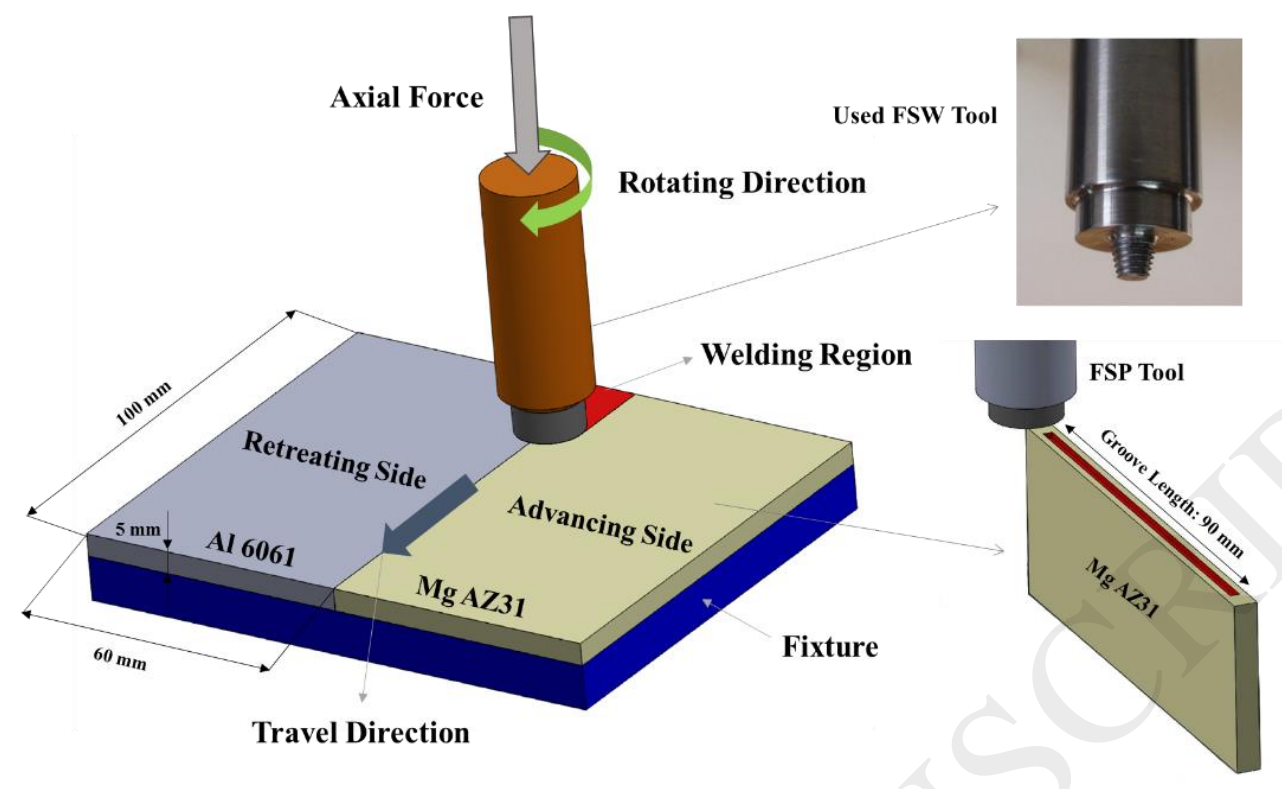

Fig. 1. A schematic representation of the FSW/FSP processes and a view of used FSW tool.

\section{Table 2}

FSP and FSW process parameters.

\begin{tabular}{|c|c|c|c|c|c|c|c|}
\hline Process & $\begin{array}{c}\text { Rotational Speed } \\
(\text { rpm })\end{array}$ & $\begin{array}{l}\text { Traveling speed } \\
\qquad(\mathrm{mm} / \mathrm{min})\end{array}$ & $\begin{array}{c}\text { Tilt angle } \\
\text { (degree) }\end{array}$ & $\begin{array}{l}\text { Axial force } \\
\qquad(\mathrm{KN})\end{array}$ & Position & Offset & $\begin{array}{c}\text { Number of } \\
\text { pass }\end{array}$ \\
\hline FSP & 800 & 50 & 3 & 3 & on faying surface of $\mathrm{Mg}$ & - & 3 pass \\
\hline FSW & $550-600-650$ & 35 & 3 & 3 & $\begin{array}{c}\text { Mg (advancing side)/ } \\
\text { Al (retreating side) }\end{array}$ & $\begin{array}{c}1 \mathrm{~mm} \\
\text { toward } \mathrm{Mg}\end{array}$ & 1 pass \\
\hline
\end{tabular}

Table 3

Sample identification and process conditions.

\begin{tabular}{|c|c|c|c|c|c|c|c|}
\hline Sample identification & 1 & 2 & 3 & 4 & 5 & 6 & 7 \\
\hline Rotational speed (rpm) & 550 & 550 & 600 & 600 & 650 & 650 & 650 \\
\hline Traveling speed $(\mathrm{mm} / \mathrm{min})$ & 25 & 35 & 25 & 35 & 25 & 35 & 35 \\
\hline Condition & Reinforced & Reinforced & Reinforced & Reinforced & Reinforced & Reinforced & Non-Reinforced \\
\hline
\end{tabular}




\section{Table 4}

Detailed features of the tool used for FSP and FSW.

\begin{tabular}{|c|c|c|c|c|c|c|c|}
\hline Process & Tool material & $\begin{array}{l}\text { Shoulder } \\
\text { diameter } \\
(\mathrm{mm})\end{array}$ & $\begin{array}{l}\text { Surface of } \\
\text { shoulder }\end{array}$ & Shape of pin & $\begin{array}{l}\text { Big diameter } \\
\text { of pin }(\mathrm{mm})\end{array}$ & $\begin{array}{c}\text { Small } \\
\text { diameter of } \\
\text { pin }(\mathrm{mm})\end{array}$ & $\begin{array}{l}\text { Length of pin } \\
(\mathrm{mm})\end{array}$ \\
\hline FSP & H13 Steel & 15 & Concave & Pinless & - & - & \\
\hline FSW & H13 Steel & 15 & Concave & Frustum & 6 & 4 & 4.8 \\
\hline
\end{tabular}

\subsection{Microstructural characterization}

In order to carry out the metallographic experiments, cross-sectional samples were cut vertical to the FSW direction. Microstructural preparation was carried out according to ASTM-E3 standard test method. The joints were first polished mechanically to 4000 grit, followed by polishing using a solution of $\mathrm{Al}_{2} \mathrm{O}_{3}$ up to $1 \mu$ m powder size. A twostep procedure was performed to etch the polished metallographic samples of the joints. The first step showed the microstructure of the AZ31 side and the second one showed the structure in the $6061 \mathrm{Al}$ side. In the first step, the samples were etched by a solution containing nitric acid, acetic acid and oxalic acid (1 ml each) in $150 \mathrm{ml}$ of distilled water for 5 seconds. In the second step, the samples were etched with a solution of $2 \mathrm{ml}$ of hydrofluoric acid, $3 \mathrm{ml}$ of hydrochloric acid and $5 \mathrm{ml}$ of nitric acid in $190 \mathrm{ml}$ of distilled water for 60 seconds.

The microstructure was observed using optical microscopy (OM-Meiji Techno IM7200 and Olympus GX51), field emission scanning electron microscopy (FESEM-JEOL JSM-7001F operated at $20 \mathrm{kV}$ ) and high resolution transmission electron microscopy (HRTEM-Philips CM200 and Philips C2100 at an accelerating voltage of $200 \mathrm{kV}$ ). Conventional mechanical polishing was used to prepare TEM samples. The samples were first cut and then ground to a thickness of lower than $100 \mu \mathrm{m}$ using 1000 abrasive paper. Afterwards, a $3 \mathrm{~mm}$ disc was punched out from the sample. According to the optical micrograph, the region containing IMCs next to the advancing side and consisting of the $\mathrm{Mg} / \mathrm{Al}$ interface, was chosen as the punch area. Using diamond paste, the punched samples were then polished and ion milling was applied for thinning in the final step. 


\subsection{Mechanical characterization}

Tensile samples in sub-sized scale were prepared vertical to the FSW direction, according to ASTM-E8 standard test method. For tensile tests, an INSTRON-5502 universal testing machine was employed at room temperature at a strain rate of $0.5 \mathrm{~mm} / \mathrm{min}$. The fracture surface was studied by a FEI Quanta 200 SEM equipment. The microhardness profiles across the mid-thickness of the two metallographic samples, as a case study of two typical behaviors of reinforced samples, were compared with that of non-reinforced specimens. For this purpose, Micro Vickers hardness tester (Buehler Micromet 2) with $25 \mathrm{~g}$ load and $10 \mathrm{~s}$ holding time was employed. Each indentation point was $0.5 \mathrm{~mm}$ from the other.

\section{Results and discussion}

\subsection{Process}

Fig. 2 shows the distribution of nanoparticles on the faying surface of the Mg alloy after 1, 2 and 3 FSP passes. Fig. 2(a) shows the SEM image of the agglomerated SiC particles in a single FSP pass. The SiC nanoparticles are found concentrated in a jagged line around the initial groove. Fig. 2(b) shows nanoparticle distribution in the two FSP pass specimens. The sign of the initial groove has disappeared and the agglomeration of $\mathrm{SiC}$ nanoparticles is significantly lower than the previous sample, but the distribution of nanoparticles is still uneven in the magnesium matrix. However, a better distribution of $\mathrm{SiC}$ nanoparticles on the faying surface of Mg alloy in the three FSP pass specimen is observed in Fig. 2(c), in which the agglomeration of nanoparticles is very low and a uniform distribution is displayed. Fig. 2(d) represents the EDS results from region D marked in Fig. 2(a). The SiC peak verifies the presence of SiC rich areas inside the magnesium matrix. Further FSP passes reduce the cluster size of the particles and improve the reinforcement distribution. Improved distributions of the nanoparticle are due to the separation of the particles from the clusters during every pass and broken onion rings shaped in prior FSP pass (Azizieh et al., 2011). 

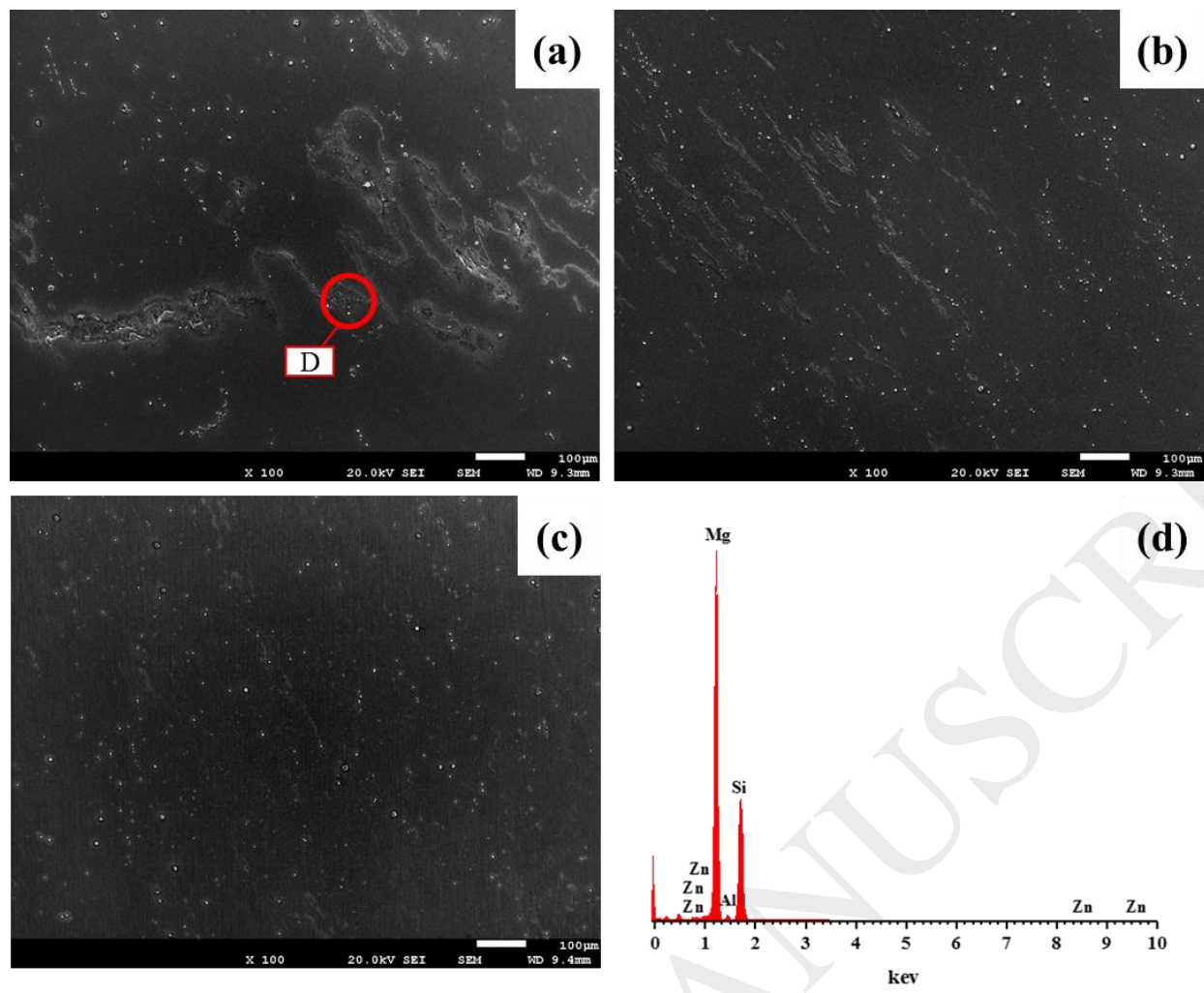

Fig. 2. FESEM images of the friction stir processed faying surface of $\mathrm{Mg}$ made at $800 \mathrm{rpm}$ and $50 \mathrm{~mm} / \mathrm{min}$ : (a) 1 pass, (b) 2 passes, (c) 3 passes, (d) EDS peaks of point D denoted in Fig. 2(a).

\subsection{Joint appearance and Macrostructure}

Fig. 3 shows the macrostructure of $\mathrm{Mg} / \mathrm{Al}$ friction stir welded joints at different rotational and traveling speeds after three FSP passes on the faying surface of the Mg strip. The selected regions are shown in larger magnification in Fig. 4. In the case of sample 1, low rotational speed causes an uneven surface and a zigzag line indicating insufficient intermixing. Cavity defects with different sizes exist in this sample (Fig. 4(a,b)), but they disappear after increasing the rotational speed. Under the low heat input condition, different plastic flows occur between $\mathrm{Al}$ and $\mathrm{Mg}$. There is probably a discontinuity in the material flow as a result of cavity formation.

In specimen 2, an evident crack defect (Fig 4(c)) exists along the interface regardless of inappropriate interlocking metals under low heat input condition.

When the heat input increases (higher rotational speeds), cracks and voids are not observed while smooth semicircular traces can be observed in the weld surface. Moreover, due to the good penetration of $\mathrm{Al}$ and $\mathrm{Mg}$ into each other, a 
more homogenous mixing is obtained. These observations are consistent with the flow pattern of these samples (see macrostructures), which shows appropriate intermixing of magnesium and aluminum alloys in the stirring zone.

The formation of onion like rings and the presence of some microcrack inside the severely deformed zone of sample 5 are obvious (see Fig. 4d). This sample was exposed to the highest temperature during FSW process (maximum rotational speed and minimum traveling speed). These conditions provide a good plastic flow to form onion rings in the stirring zone, but can form more IMC in the nugget zone and encourage welding brittleness and crack formation, as reported by Firouzdor and Kou (2010).

Two distinct zones, (1) a banded structure (BS) zone and (2) a severely deformed zone (SDZ) in the middle of the weld nugget (Liang et al., 2013) can be observed in the joints; particullary in specimen 6. Liang et al. (2013) and Shi et al. (2017) reported that the BS zone is responsible for most of the welded joint failures due to the presence of a large number of IMC. Here, to pay particular attention and further strengthening of this area, groove design and particle incorporation was made on the $\mathrm{Mg}$-side. 


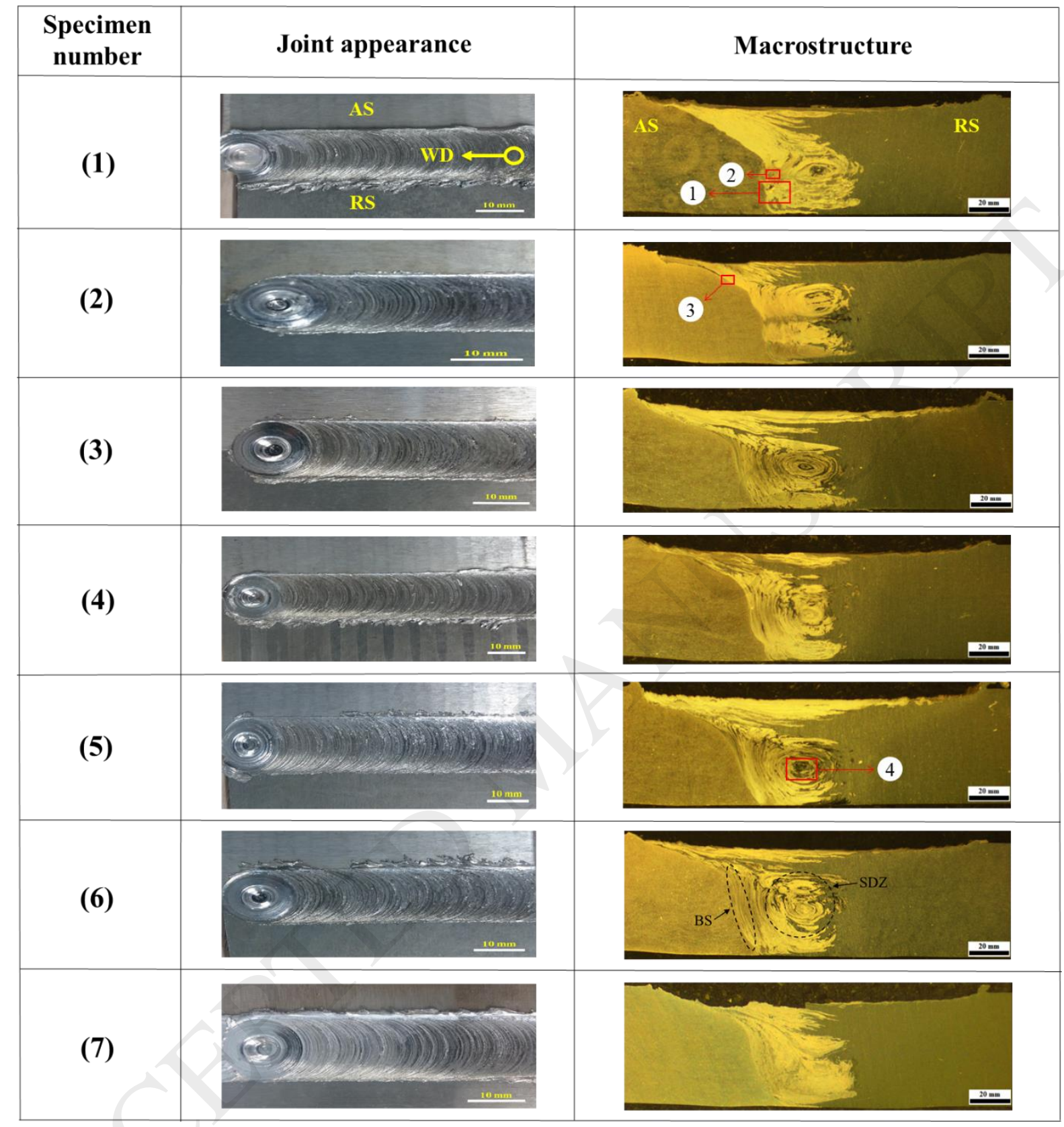

Fig. 3. Joints appearance and macrostructure of different samples welded using various welding conditions, namely rotational and transversal speeds. Processing conditions of each sample are listed in Table 3. 

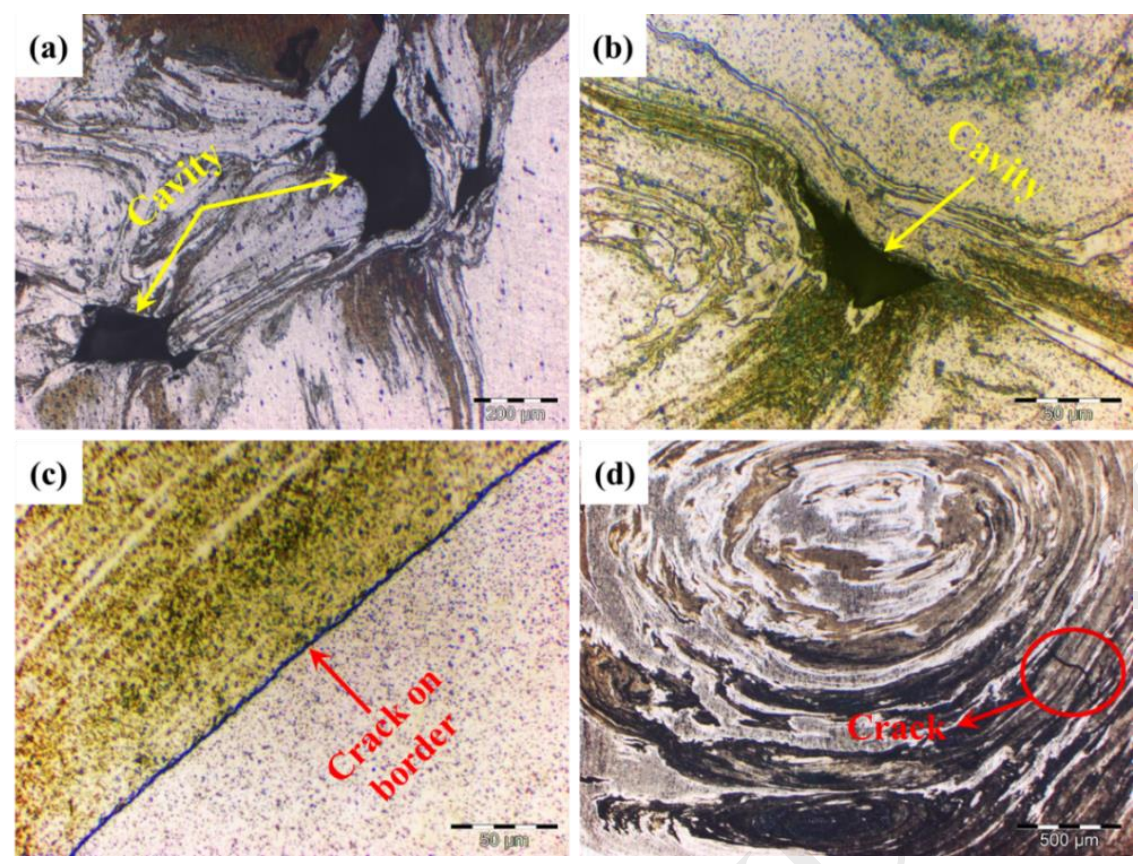

Fig. 4. Enlarged graph of areas pointed in Fig 3: (a,b) presence of cavity in the stirred zone, (c) continuous crack on the border of magnesium alloy and nugget, (d) microcrack inside the severely deformed zone.

\subsection{Microstructural observation}

Sample 6 has been chosen for a detailed microstructural observation. Figs. 5(a-d) present the microstructures of the typical areas of sample 6, corresponding to the heat affected zone (HAZ), thermomechanically affected zone (TMAZ), stirred zone (SZ) and interface between SZ and banded structure zone on the magnesium side.

Fig. 5(a) shows the interface between HAZ and TMAZ while Fig. 5(b) illustrates the interface between TMAZ (characterized by elongated grains) and SZ area. A dramatic reduction of the grain size in the stirred zone and the area adjacent to the banded structure zone can be observed in Figs. 5(c,d). The grain size is considerably finer than that of sample 7 (same conditions as sample 6, but without reinforcement particles), also shown in Figs. 5(e,f). The mean grain size on the $\mathrm{Mg}$ side reduced from 13 to $4 \mu \mathrm{m}$ by just adding the reinforcing particles.

In the case of the non-reinforced sample, the material experiences severe plastic deformations, resulting in the formation of fine grains by continuous dynamic recrystallization (CDRX) at elevated temperatures during FSW. A similar finding was reported by El-Rayes and El-Danaf (2012) and Morisada et al. (2006). In the reinforced samples, agglomerated particles were found to function as the preferred sites for nucleation for the formation of new grains and CDRX can be promoted, based on the particle stimulate nucleation mechanism, as reported by Bahrami et al. (2014) 
and Barmouz et al. (2011). In addition, according to Azizieh et al. (2011) and El-Rayes and El-Danaf (2012), the subsequent grain growth after CDRX can be prevented because of the particles, which act as barriers against grain boundaries motion and thus finer grains will be obtained.
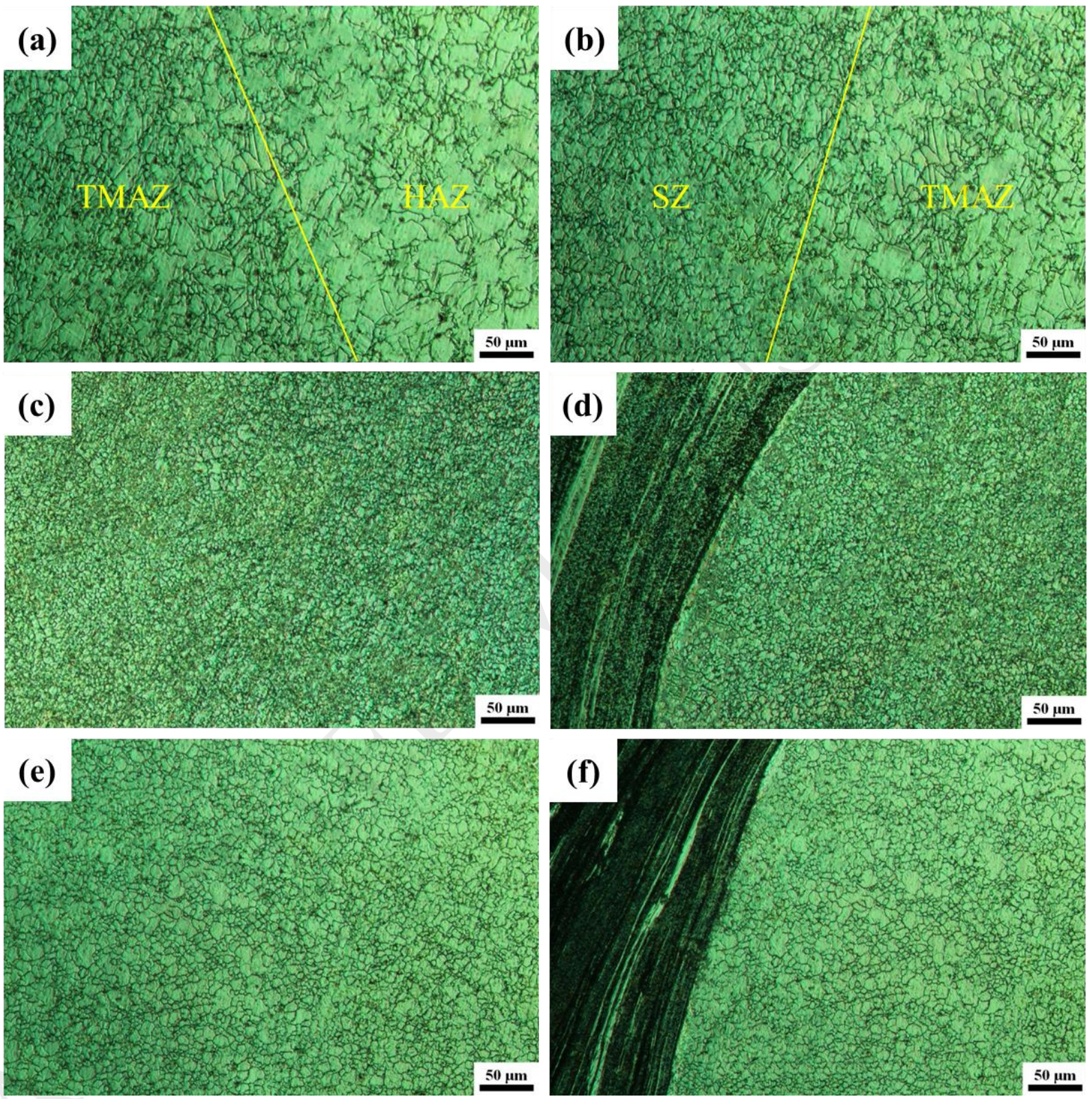

Fig. 5. Microstructure of typical joint areas in the advancing side of reinforced (sample 6) and non-reinforced (sample 7) specimens made at $650 \mathrm{rpm}$ and $35 \mathrm{~mm} / \mathrm{min}$ : (a) interface of HAZ and TMAZ regions in reinforced sample, (b) interface of

TMAZ and SZ in reinforced sample, (c) SZ in reinforced sample, (d) interface of SZ and BS zone in reinforced sample, (e) SZ in non-reinforced sample, (f) interface of SZ and BS zone in non-reinforced sample. 
A low magnification cross-sectional view of the samples made at $650 \mathrm{rpm}$ and $35 \mathrm{~mm} / \mathrm{min}$ is presented in Fig. 6(a). SEM analysis was performed by focusing on the severely deformed zones and borders of magnesium and aluminum alloys with nugget zone, which owned typical features, significantly distinct with similar friction stir welding joints. Figs. 6(b,c) show typical SEM images of the top and bottom interface between Mg and nugget. A banded structure zone with light and dark gray bands is clear. The alternative ordering of light and dark gray bands by different chemical content can be clarified with the alternative white and dark layers observed in the optical graph (Fig. 6(d)).

EDS analysis was performed at the locations marked as points 1 to 5 to derive the chemical nature of the IMC. The results are listed in Table 5. The light gray phase in Fig. 6(c) (points 1) consists of both magnesium and aluminum (the amount of magnesium being much greater) and the background with dark gray contrast is the magnesium rich phase. The light gray band seems to be the $\mathrm{Al}_{12} \mathrm{Mg}_{17}(\gamma)$ phase.

A particular SEM graph of the aluminum border is shown in Fig. 6(d). In this figure, a light etching layer with a thickness of around $2 \mu \mathrm{m}$ on interface is a sign of the formation of IMCs. EDS analysis of point 2 indicates that the compound is $\mathrm{Al}_{3} \mathrm{Mn}_{2}(\beta)$.

Three distinct zones in the top, center and bottom of the severely deformed zone are shown in Figs. 6(e-g), respectively. Different plasticity of magnesium and aluminum and severe deformation during FSW process cause intercalated structures. The severely deformed zone displayed complex and disordered patterns, represented by swirls and vortexes of magnesium and aluminum, which correspond to the spiral flow of metals in the FSW process (Fu et al., 2015; Mofid et al., 2012). As observed, due to the temperature reduction from the top to the bottom of the intercalated zone, the formation of IMCs is suppressed significantly.

Inside the stirring zone, cracks are accompanied by intermetallic compounds, as shown in Fig. 6(g). EDS analysis shows about 42 wt. \% $\mathrm{Mg}$ at point 5, which suggests that the IMC compound is $\mathrm{Al}_{3} \mathrm{Mg}_{2}$. Since $\mathrm{Al}_{3} \mathrm{Mg}_{2}$ exists at the cracks, they correspond to liquation cracks, as reported by Firouzdor and Kou (2010) and Mofid et al. (2012).

Figs. 6(h,i) provide elemental distribution of magnesium and aluminum in the severely deformed zone. It is obvious that $\mathrm{Al}$ and $\mathrm{Mg}$ have good intermixing. The reaction between magnesium and aluminum during FSW is revealed by the presence of both magnesium and aluminum elements in the areas shown by arrows. 

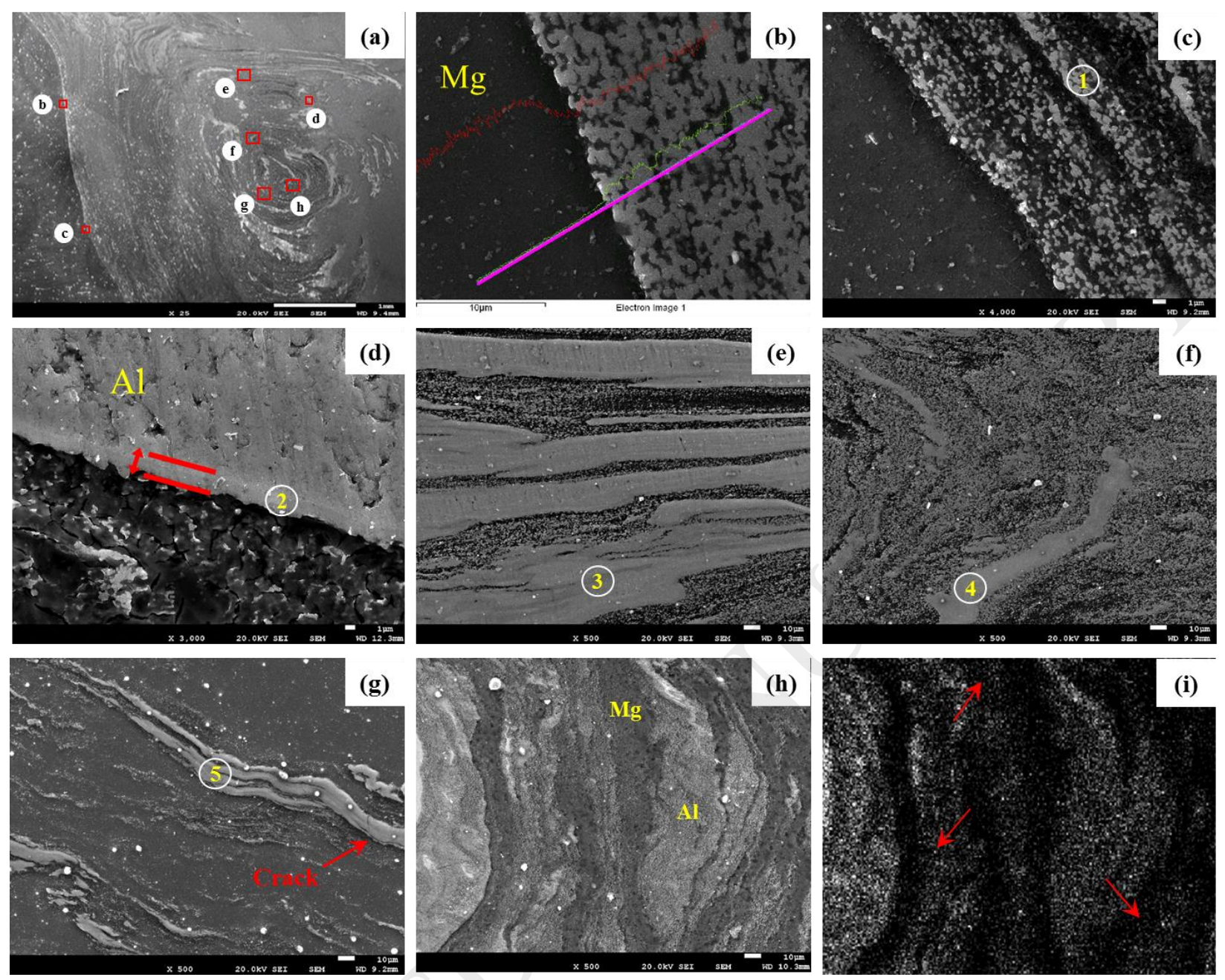

Fig. 6. FESEM micrograph and EDS examination of reinforced sample made at $650 \mathrm{rpm}$ and $35 \mathrm{~mm} / \mathrm{min}$ : (a) cross-sectional view of joint, (b-h) Enlarged graph of areas pointed in (a), (i) EDX mapping of the areas pointed in (h).

Table 5

Compositions (wt. \%) determined by EDS at locations demonstrated in Fig. 6

\begin{tabular}{ccccc}
\hline Location & $\mathrm{Mg}$ & $\mathrm{Al}$ & Others & Possible Phase(s) \\
\hline 1 & 69.19 & 28.44 & 2.37 & $\mathrm{Mg}+\mathrm{Al}_{12} \mathrm{Mg}_{17}(\gamma)$ \\
2 & 41.53 & 57.28 & 1.19 & $\mathrm{Al}_{3} \mathrm{Mg}_{2}(\beta)$ \\
3 & 30.37 & 68.57 & 1.06 & $\mathrm{Al}^{2} \mathrm{Al}_{3} \mathrm{Mg}_{2}(\beta)$ \\
4 & 60.49 & 38.00 & 1.51 & $\mathrm{Al}_{12} \mathrm{Mg}_{17}(\gamma)$ \\
5 & 42.04 & 57.16 & 0.8 & $\mathrm{Al}_{3} \mathrm{Mg}_{2}(\beta)$ \\
\hline
\end{tabular}


EDS analysis in the form of chemical composition mapping was also used for examination of the distribution of $\mathrm{SiC}$ nanoparticles in the stirring zone of the welded samples. For sample 2, the FESEM micrograph and SiC distribution are demonstrated in Figs. S2 (a,b), respectively. It can be observed that nanoparticle agglomeration at the stirred zone will increase with reduction in the rotational speed. Defects such as crack and micro-voids are speculated to form beside the agglomeration zones due to the poor adhesion between the matrix and aggregated particles, as reported by Bodaghi and Dehghani (2017). The FESEM micrograph of the stir zone of sample 6 is shown in Fig. S2(c). The map of $\mathrm{SiC}$ distribution in this area is depicted in Fig. S2(d), which shows the uniform particle distribution in this sample.

Fig. 7 exhibits the presence of $\mathrm{SiC}$ nanoparticles in various regions of sample 6 in addition to EDS spectra for each micrograph. It is obvious from these images that $\mathrm{SiC}$ particles have uniform dispersion in different regions. As previously indicated, the selection of suitable process parameters such as rotation and travel speeds can improve the homogenous dispersion of nanoparticles. Abdolahzadeh et al. (2014) and Bahrami et al. (2014) have reported that the uniform distribution of particles is one of the most important concerns in grain refining of the stirred zone and producing reinforced composites. 

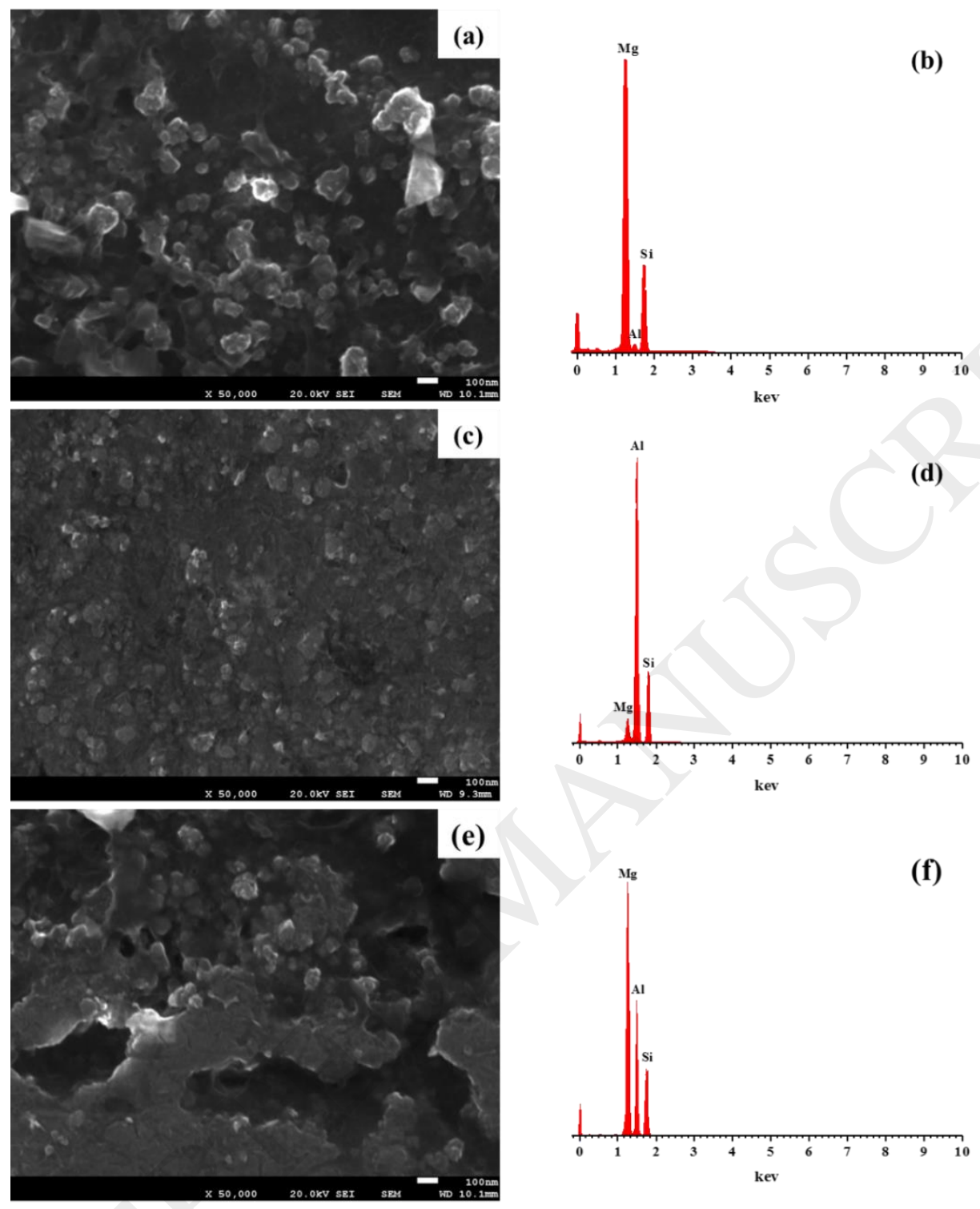

Fig. 7. FESEM image and EDS peaks of different $\mathrm{SiC}$ reach regions in FS welded specimen at $650 \mathrm{rpm}-35 \mathrm{~mm} / \mathrm{min}:(\mathrm{a}, \mathrm{b}) \mathrm{Mg}$ matrix, (c, d) $\mathrm{Al}$ matrix, (e, f) interface of $\mathrm{Al}$ and $\mathrm{Mg}$.

Fig. 8 represents some TEM images from the stirred zone of sample 6. Fig.8(a) shows a typical microstructure from the dispersion of $\mathrm{SiC}$ nanoparticles in $\mathrm{Mg}$ matrix. The presence of some dislocation structures is also shown in Fig. 8(a). The area shown by the arrow presents dislocations propagating from the grain boundaries. EDS peaks obtained from location B (Fig. 8(b)) confirm the presence of SiC particles in Mg matrix. Selected area diffraction pattern, shown in Fig. 8(d), was also used for identifying SiC particles. 
EDS peaks from location C confirm the existence of $\mathrm{Al}_{12} \mathrm{Mg}_{17}(\gamma)$ (Fig. 8(c)). Therefore, in Fig. 8(a), a $\gamma$-phase particle encircled with magnesium grains can be observed. The diameter of the $\gamma$-phase grain is in micron scale, which is consistent with Kostka et al. (2009) and Firouzdor and Kou's (2010) results. The existence of both $\gamma$-phase and magnesium in this area of the stirred zone is compatible with the eutectic reaction $(\gamma)+(M g) \rightarrow L$ at $703 \mathrm{~K}\left(430{ }^{\circ} \mathrm{C}\right)$ in $\mathrm{Mg}-\mathrm{Al}$ phase diagram.

A higher magnification of $\mathrm{SiC}$ nanoparticles and a triple point of grains in the stirred zone are shown in Figs. 8(e, $\mathrm{f})$, respectively. It can be observed that there is an appropriate bonding between the matrix and the reinforcements. Fig. $8(\mathrm{~g})$ presents high magnification of dislocation structure in the stirred zone.
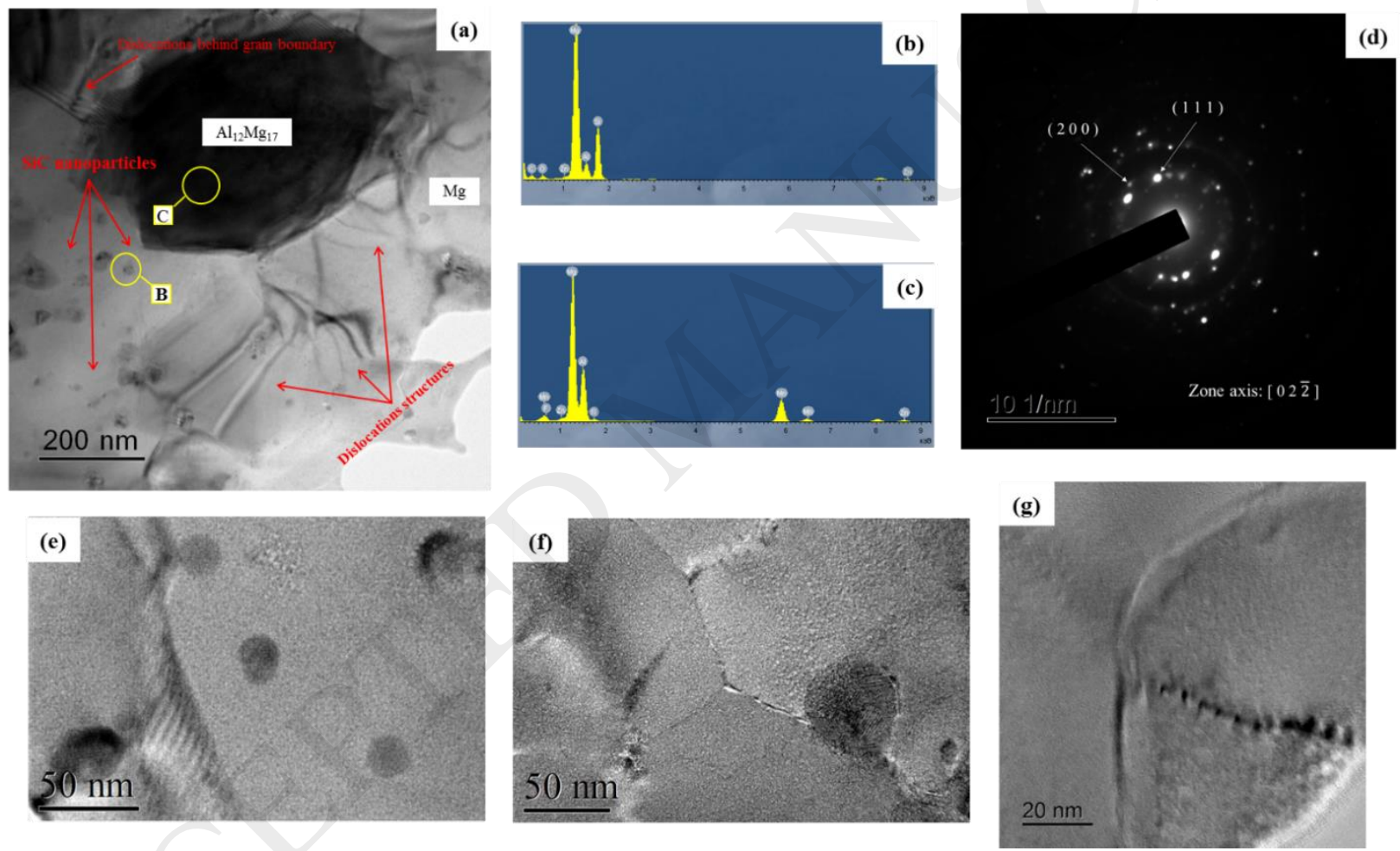

Fig. 8. TEM images, EDS analysis and electron diff raction pattern in stirred zone of the weld made at $650 \mathrm{rpm}-35 \mathrm{~mm} / \mathrm{min}$ : (a) bright-field image showing $\mathrm{Al}_{12} \mathrm{Mg}_{17}$ phase, $\mathrm{SiC}$ particles in $\mathrm{Mg}$ matrix and dislocations structure, (b, c) EDS peaks of points B and $\mathrm{C}$ denoted in fig 8(a), (d) the selected area diff raction pattern in $\left[\begin{array}{lll}0 & 2 & 2\end{array}\right]$ Zone axis identifying SiC particles, (e) high magnification of SiC nanoparticles, (f) triple point of grains and (g) high magnification of dislocation structure. 


\subsection{Mechanical properties}

\subsubsection{Hardness}

Fig. 9 shows the comparison of the microhardness profiles of samples 2, 6 and 7.

In all the welded samples, hardness significantly increases in the stirred zone. Fluctuations in the points with high hardness could be related to the presence of SiC rich regions or formation of IMCs. The areas with low hardness could be due to $\mathrm{SiC}$ free regions or lack of intermetallic compounds in the SZ. Fluctuations in sample 6 are lower than those in sample 2, which is compatible with microstructural observations in the previous section (Fig. S2). Indeed, the homogenous distribution of the particles in sample 6 encourages decreasing difference between hardness of SiC rich and free regions.

Besides, a comparison of reinforced (samples 2 and 6) and non-reinforced samples (sample 7) reveals that the addition of nanoparticles increases the value of microhardness. As shown in Fig. 5, it is obvious that the reinforced sample has significantly finer grains than the non-reinforced sample. In addition, stability against dislocation motion is caused by the high hardness of these ceramic particles, giving rise to higher hardness in the nugget zone. This is also in good agreement with the report by Fallahi et al. (2017).

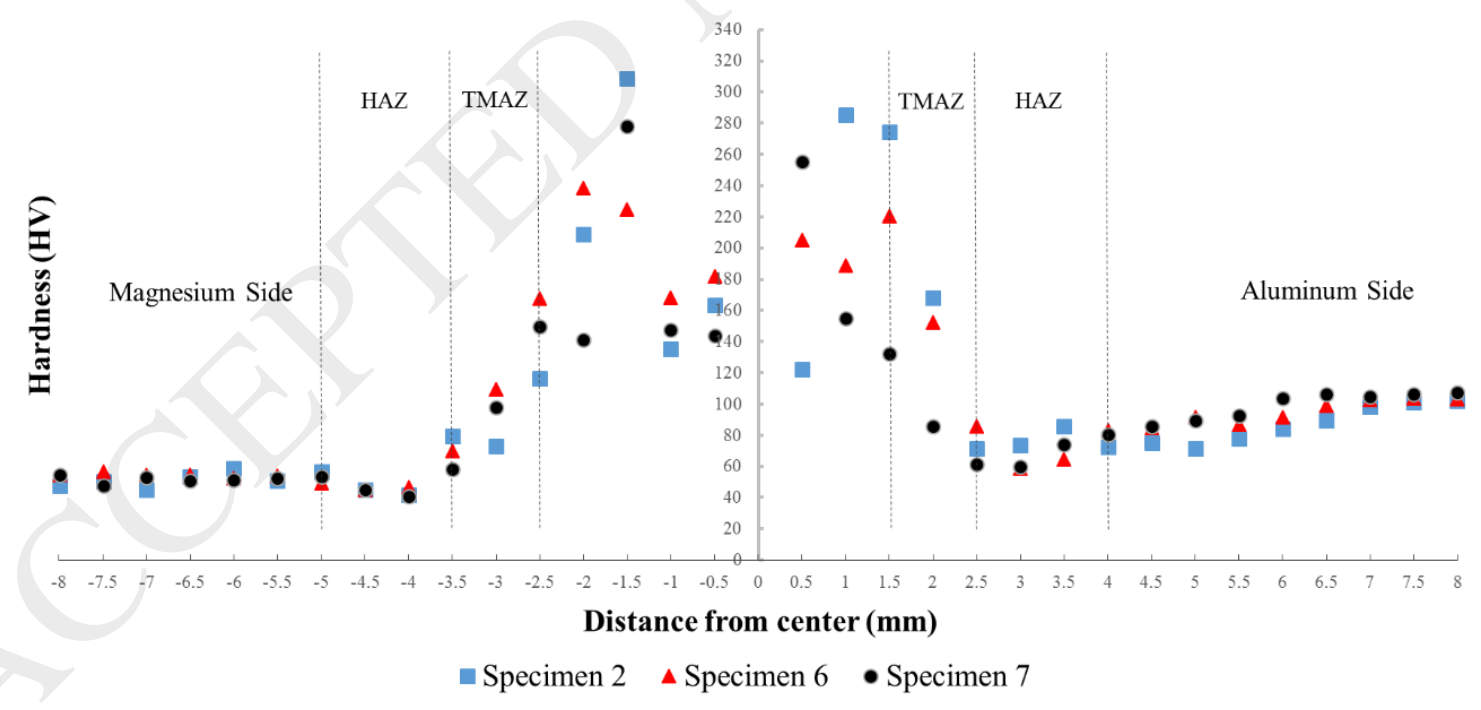

Fig. 9. Microhardness behavior across the centerline of samples 2, 6 and 7 


\subsubsection{Tensile properties}

Mechanical properties in terms of tensile test (UTS and elongation (\%)) for all specimens are illustrated in Fig. 10. For sample 1, as displayed in Figs. 4(a,b), the major reason for the lowest UTS and elongation is the presence of cavities, which reduce the effective working area and promote stress concentration.

Although there are no cavities or voids in sample 2, the low loads in this case can be attributed to the presence of a long crack on the border of $\mathrm{Mg}$ and nugget, which continues throughout the joint (Fig. 4(c)).

Sample 5 was subjected to the highest heat input (lowest traveling speed and highest rotational speed), which result in more intermixing of $\mathrm{Al}$ and $\mathrm{Mg}$ as a result of the softening of materials. In dissimilar joints ,this may enhance the possibility of forming IMC layers and increase weld brittleness, causing the loss of tensile properties of the weld, according to Rafiei et al. (2017). Moreover, another reason for the low tensile strength in this sample may be the presence of crack in the stirred zone (Fig 4(d)).

On the contrary, the best UTS and elongation values are observed in sample 6, which are associated with its small grain size and appropriate distribution of nanoparticles.

Hall-Petch and Orowan-Ashby equations can clarify this finding. The dependence of strength on grain size is described by Hall-Petch equation, according to Dieter and Bacon (1986):

$\sigma=\sigma_{\mathrm{i}}+\mathrm{kD}^{-\frac{1}{2}}$

Where $\sigma_{\mathrm{i}}$ is a friction stress, $\mathrm{k}$ is material constant parameter and $\mathrm{D}$ is the grain size. The role of interparticle spacing in the strengthening by second phase particles may be defined by Orowan-Ashby equation, as observed by Dieter and Bacon, (1986):

$\Delta \sigma \approx \mathrm{k}^{\prime} \lambda^{-\frac{1}{2}}$

Where $\mathrm{k}^{\prime}$ and $\lambda$ are a constant and the interparticle spacing, respectively.

Strengthening is high when grain size and interparticle spacing reduce, considering equations (1) and (2). Furthermore, the ductility and thus the elongation percent reduction are increased by the grain size and interparticle spacing.

In addition, decreasing both the grain size and interparticle spacing increases the ductility and thus the elongation percent, as previously demonstrated by Abdollahzadeh et al. (2017) and Azizieh et al. (2011). Consequently, these results suggest that during the processing of the current samples containing $\mathrm{SiC}$ particles, none of the high rotational and low traveling speeds (maximum heat input) or low rotational and high traveling speeds (minimum heat input) can 
provide the best mechanical properties of the weld since the first one encourages grain growth and formation of intermetallic compounds and the second one boosts the interparticle spacing and microstructural defects.

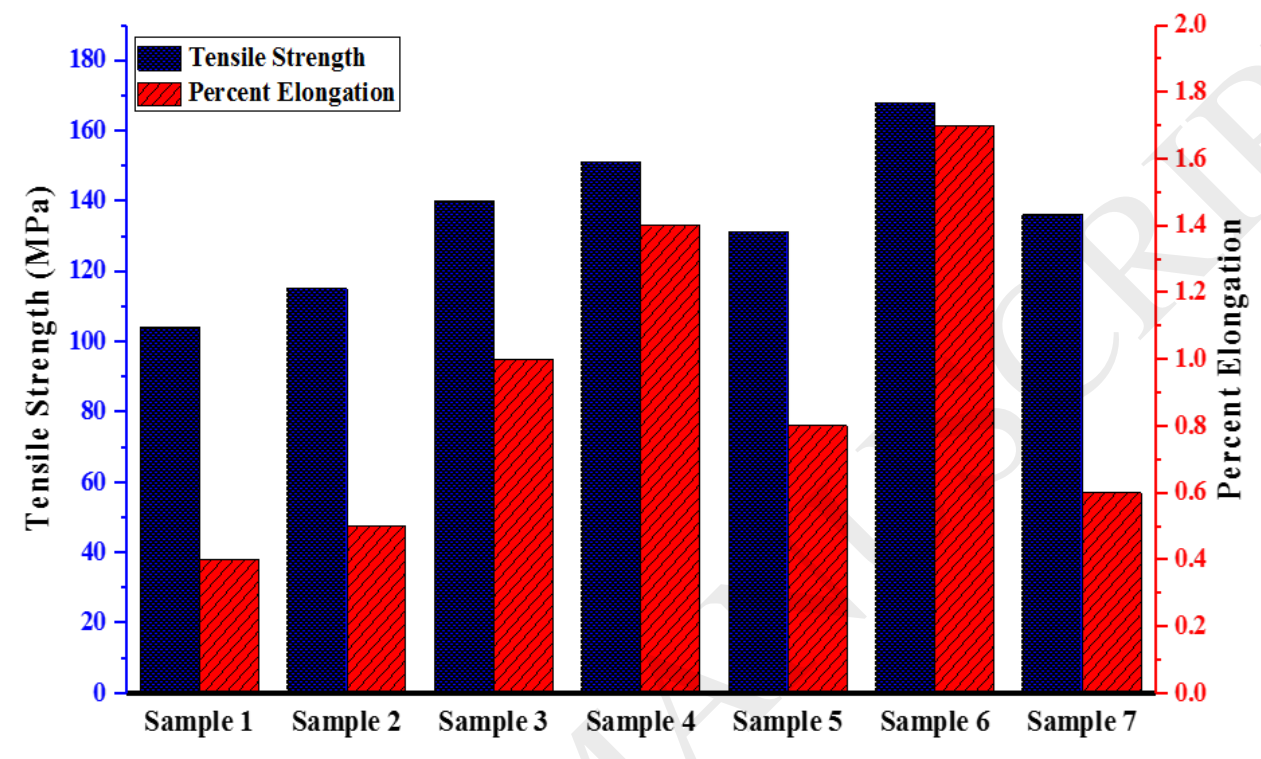

Fig. 10. UTS values and elongation percent of the welds.

\subsubsection{Fractography}

SEM fractographs of all the samples are presented in Fig. 11. All the specimens were fractured along the banded structure zone adjacent to the AS. A fully brittle fracture is observed in the non-reinforced sample (Fig. 11(g)). Fracture surfaces show coarse cleavage facets and crack propagation. Samples 1 (Fig. 11(a)) and 2 (Fig. 11(b)) show cleavage facets. However, the size of the cleavage facets has a fine texture. Brittle behavior can be due to the presence of microstructural defects already pointed out (Figs. 4(a, b)). The fracture surface of sample 5 (Fig. 11(e)) is similar to an intergranular brittle fracture pattern. This sample has experienced the highest temperature during the FSW process (maximum rotational speed and minimum traveling speed). Hence, the formation of IMCs is strongly promoted, which can encourage brittle fracture of the joint. 
Fracture surfaces of samples 3, 4 and 6 (Figs. $11 \mathrm{c}, \mathrm{d}$, f) show the presence of shallow dimples. As it can be observed in Fig. 11(f), the dimples are more numerous and deeper in sample 6. The presence of dimples in these samples indicates changing failure behavior from brittle to ductile mode.

Ductility results are fully consistent with fracture micrographs. Low elongations in samples 1,2,5 and 7 are related to the absence of dimples (Figs. 11 a, b, e, g). A similar low elongation has been reported by Bahrami et al. (2014). Moderate elongation for sample 3 is in accordance with the presence of shallow dimples in this sample (Fig. $11 \mathrm{c}, \mathrm{d}$ ). Specimen no. 6 showed the highest elongation and its corresponding fractography displays deep equiaxed dimples, suggesting a strong ductile fracture component (Fig. 11f). Sharifitabar et al. (2011) related the concurrent enhancement of elongation and UTS to the Orowan strengthening, associated with good distribution of nanosized particles in the matrix along with grain refinement.

The X-ray diffraction patterns of fracture surface of sample 6 for the $\mathrm{Al}$ and $\mathrm{Mg}$ sides, respectively, are shown in Fig. S3. $\mathrm{Mg}_{17} \mathrm{Al}_{12}$ and $\mathrm{Al}_{3} \mathrm{Mg}_{2}$ intermetallic compounds were detected on both $\mathrm{Mg}$ and $\mathrm{Al}$ sides, which is in agreement with the possible compounds shown in Table 5. 

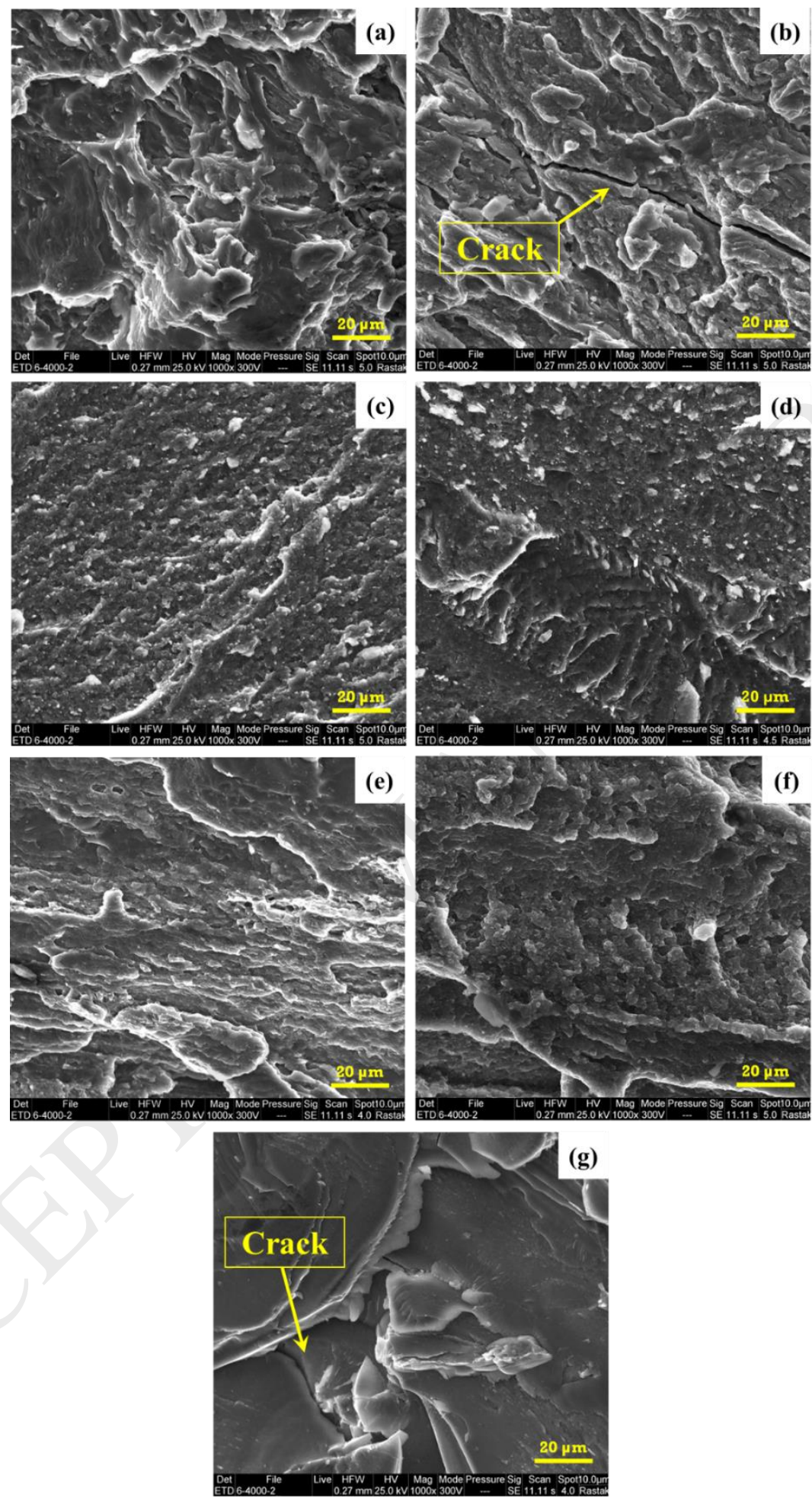

Fig. 13. Micro fractographs of samples: (a) number 1, (b) number 2, (c) number 3, (d) number 4, (e) number 5, (f) number 6 and (g) number 7 . 
Macro fractographs of samples 6 and 7 after the tensile test are presented in Fig. S4. There are two different typical types of fracture paths in the banded structure zones. Liang et al. (2013) and Shi et al. (2017) noted that the fracture along the banded structure zone can be comprehended considering three facts: 1) Abundant brittle IMCs are formed in the BS zone of all the welds, which can facilitate the propagation of cracks. 2) The angle between the direction of the IMC bands in the BS and tensile is $45^{\circ}$, in which case, the maximum shear stress is forced to the IMC bands. 3 ) During the solidification, the fracture might initiate from the hot cracks formed in the BS.

Considering the direction of the curved IMC/Mg interface, the fracture route for sample 6 (reinforced sample) in macro scale is zigzag shaped, (Fig. S4(a)), while for sample 7 (non-reinforced sample), this route has a relatively straight shape along the direction of bands (Fig. S4(b)). The crack initiates from continuous IMC lamella and propagates along the $\mathrm{Mg} / \mathrm{IMC}$ interface. During crack propagation, IMCs are not present in certain regions of the fracture route and crack propagation occurs through magnesium. In the case of the reinforced sample, due to a significant grain size reduction of adjacent $\mathrm{Mg}$ alloy, tensile properties improve. This causes more crack deflection and makes a difficult route for fracture (Fig. S4 (a)). In contrast, in the case of the non-reinforced sample, the adjacent Mg alloy displays lack of ductility and the macro fractograph (Fig. S4(b)) clearly shows the easy path for crack propagation during the tensile test. This means that higher energy is needed for the fracture to take place in the reinforced sample. Consequently, the mechanical properties of sample 6 are expected to be superior compared with sample 7. This is in accordance with the results shown in Fig. 10.

\section{Conclusions}

- The application of FSP process prior to FSW successfully prevented the agglomeration of particles. Therefore, after 3 passes of FSP process, appropriate nanoparticles were appropriately distributed on the faying surface of magnesium strip.

- The optimal travel and rotation speeds were $35 \mathrm{~mm} / \mathrm{min}$ and $650 \mathrm{rpm}$, respectively, based on the microstructural observations and mechanical tests of the welded specimens. The UTS of the reinforced sample was $28 \%$ higher than that of the non-reinforced sample and the elongation improved about 3 times.

- $\mathrm{SiC}$ nanoparticles were effective on the grain refining of the nugget. These particles prevented the grain boundary motion and acted as preferable nucleation sites. Thus, the mean grain size on the $\mathrm{Mg}$ side reduced 
from $13 \mu$ in the non-reinforced sample to $4 \mu \mathrm{m}$ in the reinforced one in the samples prepared at the travel speed of $35 \mathrm{~mm} / \mathrm{min}$ and rotation speed of $650 \mathrm{rpm}$.

- The mean microhardness of the stirred zone of the reinforced sample was greater than that of the nonreinforced sample due to the presence of ceramic nanoparticles $(\mathrm{SiC})$ with high hardness, their effect on increasing the grain size through Zener effect and prevention of dislocation mobility. The low hardness fluctuations of the sample welded at $35 \mathrm{~mm} / \mathrm{min}$ and $650 \mathrm{rpm}$ confirmed the homogenous dispersion of the nanoparticles in the stirred zone.

- All the samples have fractured along the banded structure adjacent to the advancing side. The fracture of the non-reinforced sample was completely brittle and rather straight along the band orientation. However, in the reinforced samples, the fracture route changed to the ductile fracture and was zigzag shaped. In the reinforced sample, ductility increased due to a significant grain size reduction of adjacent Mg alloy. This caused more crack deflection and made a difficult route for fracture.

\section{Acknowledgment}

The authors appreciate Polytechnic University of Catalonia and K.N. Toosi University of Technology for facilities preparation of this work. Also a special thanks should be given to Dr. Jessica Calvo and Dr. Jose Antonio Benito for their intellectual and practical supports during this research.

\section{References}

Abbasi, M., Abdollahzadeh, A., Bagheri, B., Omidvar, H., 2015. The Effect of SiC Particle Addition During FSW on Microstructure and Mechanical Properties of AZ31 Magnesium Alloy. J. Mater. Eng. Perform. 24, 50375045.

Abbasi, M., Abdollahzadeh, A., Omidvar, H., Bagheri, B., Rezaei, M., 2016. Incorporation of SiC particles in FS welded zone of AZ31 Mg alloy to improve the mechanical properties and corrosion resistance. Int. J. Mater. Res. 107, 566-572.

Abdolahzadeh, A., Omidvar, H., Safarkhanian, M.A., Bahrami, M., 2014. Studying microstructure and mechanical properties of SiC-incorporated AZ31 joints fabricated through FSW: the effects of rotational and traveling speeds. Int. J. Adv. Manuf. Technol. 75, 1189-1196. 
Abdollahzadeh, A., Shokuhfar, A., Omidvar, H., Cabrera, J.M., Solonin, A., Ostovari, A., Abbasi, M., 2017. Structural evaluation and mechanical properties of AZ31/SiC nano-composite produced by friction stir welding process at various welding speeds. Proc. Inst. Mech. Eng. Part L J. Mater. Des. Appl. 1464420717708485.

Arora, A., De, A., DebRoy, T., 2011. Toward optimum friction stir welding tool shoulder diameter. Scr. Mater. 64, 9-12.

Azizieh, M., Kokabi, A.H., Abachi, P., 2011. Effect of rotational speed and probe profile on microstructure and hardness of $\mathrm{AZ} 31 / \mathrm{Al}<\mathrm{sub}>2</ \mathrm{sub}>\mathrm{O}<\mathrm{sub}>3</ \mathrm{sub}>$ nanocomposites fabricated by friction stir processing. Mater. Des. 32, 2034-2041.

Bahrami, M., Besharati Givi, M.K., Dehghani, K., Parvin, N., 2014a. On the role of pin geometry in microstructure and mechanical properties of AA7075/SiC nano-composite fabricated by friction stir welding technique. Mater. Des. 53, 519-527.

Bahrami, M., Dehghani, K., Besharati Givi, M.K., 2014b. A novel approach to develop aluminum matrix nanocomposite employing friction stir welding technique. Mater. Des. 53, 217-225.

Barmouz, M., Asadi, P., Givi, M.K.B., Taherishargh, M., 2011. Investigation of mechanical properties of Cu/SiC composite fabricated by FSP: effect of SiC particles' size and volume fraction. Mater. Sci. Eng. A 528, 17401749.

Bodaghi, M., Dehghani, K., 2017. Friction stir welding of AA5052: the effects of SiC nano-particles addition. Int. J. Adv. Manuf. Technol. 88, 2651-2660.

Buffa, G., Baffari, D., Di Caro, A., Fratini, L., 2015. Friction stir welding of dissimilar aluminium-magnesium joints: sheet mutual position effects. Sci. Technol. Weld. Join. 20, 271-279.

Chowdhury, S.H., Chen, D.L., Bhole, S.D., Cao, X., Wanjara, P., 2013. Lap shear strength and fatigue behavior of friction stir spot welded dissimilar magnesium-to-aluminum joints with adhesive. Mater. Sci. Eng. A 562, 5360.

Dieter, G.E., Bacon, D., 1986. Mechanical metallurgy. McGraw-Hill New York.

Dorbane, A., Mansoor, B., Ayoub, G., Shunmugasamy, V.C., Imad, A., 2016. Mechanical, microstructural and fracture properties of dissimilar welds produced by friction stir welding of AZ31B and Al6061. Mater. Sci. Eng. A $651,720-733$. 
Dragatogiannis, D.A., Koumoulos, E.P., Kartsonakis, I.A., Pantelis, D.I., Karakizis, P.N., Charitidis, C.A., 2016. Dissimilar friction stir welding between 5083 and $6082 \mathrm{Al}$ alloys reinforced with TiC nanoparticles. Mater. Manuf. Process. 31, 2101-2114.

El-Rayes, M.M., El-Danaf, E.A., 2012. The influence of multi-pass friction stir processing on the microstructural and mechanical properties of Aluminum Alloy 6082. J. Mater. Process. Technol. 212, 1157-1168.

Elangovan, K., Balasubramanian, V., 2008. Influences of tool pin profile and tool shoulder diameter on the formation of friction stir processing zone in AA6061 aluminium alloy. Mater. Des. 29, 362-373.

Fallahi, A.A., Shokuhfar, A., Moghaddam, A.O., Abdolahzadeh, A., 2017. Analysis of SiC nano-powder effects on friction stir welding of dissimilar Al-Mg alloy to A316L stainless steel. J. Manuf. Process. 30, 418-430.

Firouzdor, V., Kou, S., 2010a. Al-to-Mg friction stir welding: effect of material position, travel speed, and rotation speed. Metall. Mater. Trans. A 41, 2914-2935.

Firouzdor, V., Kou, S., 2010b. Formation of liquid and intermetallics in Al-to-Mg friction stir welding. Metall. Mater. Trans. A 41, 3238-3251.

Fu, B., Qin, G., Li, F., Meng, X., Zhang, J., Wu, C., 2015. Friction stir welding process of dissimilar metals of 6061 T6 aluminum alloy to AZ31B magnesium alloy. J. Mater. Process. Technol. 218, 38-47.

Kostka, A., Coelho, R.S., Dos Santos, J., Pyzalla, A.R., 2009. Microstructure of friction stir welding of aluminium alloy to magnesium alloy. Scr. Mater. 60, 953-956.

Liang, Z., Chen, K., Wang, X., Yao, J., Yang, Q., Zhang, L., Shan, A., 2013. Effect of tool offset and tool rotational speed on enhancing mechanical property of Al/Mg dissimilar FSW joints. Metall. Mater. Trans. A 44, 37213731 .

Mofid, M.A., Abdollah-Zadeh, A., Ghaini, F.M., 2012. The effect of water cooling during dissimilar friction stir welding of Al alloy to Mg alloy. Mater. Des. 36, 161-167.

Moradi, M.M., Jamshidi Aval, H., Jamaati, R., 2017. Microstructure and mechanical properties in nano and microscale SiC-included dissimilar friction stir welding of AA6061-AA2024. Mater. Sci. Technol. 1-14.

Morisada, Y., Fujii, H., Nagaoka, T., Fukusumi, M., 2006. Effect of friction stir processing with SiC particles on microstructure and hardness of AZ31. Mater. Sci. Eng. A 433, 50-54.

Padmanaban, G., Balasubramanian, V., 2009. Selection of FSW tool pin profile, shoulder diameter and material for joining AZ31B magnesium alloy-an experimental approach. Mater. Des. 30, 2647-2656. 
Pantelis, D.I., Karakizis, P.N., Daniolos, N.M., Charitidis, C.A., Koumoulos, E.P., Dragatogiannis, D.A., 2016. Microstructural study and mechanical properties of dissimilar friction stir welded AA5083-H111 and AA6082-T6 reinforced with SiC nanoparticles. Mater. Manuf. Process. 31, 264-274.

Rafiei, R., Moghaddam, A.O., Hatami, M.R., Khodabakhshi, F., Abdolahzadeh, A., Shokuhfar, A., 2017. Microstructural characteristics and mechanical properties of the dissimilar friction-stir butt welds between an Al-Mg alloy and A316L stainless steel. Int. J. Adv. Manuf. Technol. 90, 2785-2801.

Rao, H.M., Yuan, W., Badarinarayan, H., 2015. Effect of process parameters on mechanical properties of friction stir spot welded magnesium to aluminum alloys. Mater. Des. 66, 235-245.

Sharifitabar, M., Sarani, A., Khorshahian, S., Afarani, M.S., 2011. Fabrication of 5052Al/Al 2 O 3 nanoceramic particle reinforced composite via friction stir processing route. Mater. Des. 32, 4164-4172.

Sharma, V., Prakash, U., Kumar, B.V.M., 2015. Surface composites by friction stir processing: A review. J. Mater. Process. Technol. 224, 117-134.

Shi, H., Chen, K., Liang, Z., Dong, F., Yu, T., Dong, X., Zhang, L., Shan, A., 2017. Intermetallic compounds in the banded structure and their effect on mechanical properties of $\mathrm{Al} / \mathrm{Mg}$ dissimilar friction stir welding joints. J. Mater. Sci. Technol. 33, 359-366.

Sun, Y.F., Fujii, H., 2011. The effect of SiC particles on the microstructure and mechanical properties of friction stir welded pure copper joints. Mater. Sci. Eng. A 528, 5470-5475.

Tebyani, S.F., Dehghani, K., 2016. Effects of SiC nanopowders on the mechanical properties and microstructure of interstitial free steel joined via friction stir spot welding. Mater. Des. 90, 660-668.

Tebyani, S.F., Dehghani, K., 2015. Friction stir spot welding of interstitial free steel with incorporating silicon carbide nanopowders. Int. J. Adv. Manuf. Technol. 79, 343-350.

Zhao, Y., Lu, Z., Yan, K., Huang, L., 2015. Microstructural characterizations and mechanical properties in underwater friction stir welding of aluminum and magnesium dissimilar alloys. Mater. Des. 65, 675-681. 